\title{
Adaptação para Facilitar Descascar Alimentos
}

\author{
Johanna Noordhoek ${ }^{(1)}$, Aline Torquetti ${ }^{(2)}$
}

A osteoartrite (OA) é uma doença articular, com ocorrência bilateral na maioria dos casos, acometendo ambos os sexos, na idade adulta. Os sintomas incluem dor, aumento de volume e comprometimento da força e função $\operatorname{articular~}^{(1-2)}$. Rizartrose é o termo para OA acometendo a articulação trapeziometacarpiana. É mais freqüente no sexo feminino com sintomas relacionados com a execução de tarefas manuais de uso repetitivo do polegar com a preensão de força e pinça lateral ${ }^{(2)}$.

O polegar é considerado o mais especializado dos dedos, sendo responsável por cerca de $50 \%$ da função manual. Sua anatomia e biomecânica proporcionam habilidade de oponência aos outros dedos, favorecendo a execução de manipulações ${ }^{(3)}$. $\mathrm{O}$ acometimento pela rizartrose afeta a capacidade de realizar tarefas comuns, como descascar legumes, manipular chaves e $\operatorname{artesanato}^{(4)}$.

$\mathrm{O}$ tratamento da rizartrose inclui abordagem medicamentosa, técnicas de alívio dos sintomas, orientação sobre proteção articular e conservação de energia e a criação e treinamento para o uso de "splints" e adaptações ${ }^{(4)}$.
A adaptação inclui modificação de tarefas, do método de execução e/ou do ambiente onde são executadas, com objetivo de manter ou melhorar as habilidades funcionais do indivíduo com limitações ${ }^{(4)}$.

A tarefa de descascar legumes requer força e repetitividade de movimentos do polegar, causando "estresse" da articulação trapeziometacarpiana, levando a sintomatologia relacionada à rizartrose e comprometendo a função manual (Figura 1). A adaptação aqui apresentada (Figura 2) visa auxiliar a execução de tarefas por esses pacientes (Figura 3), promovendo estabilidade da articulação, proporcionada pelo cabo do adaptador; diminuição de movimentos repetitivos do polegar e da força para execução da atividade, que será deslocada da movimentação do polegar para articulações mais fortes como o punho e o cotovelo. Ao melhorar a estabilidade, a adaptação melhorará a função e deve reduzir a dor, melhorando a qualidade de vida. A adaptação é facilmente encontrada em lojas de utensílios domésticos/comércios de utilidades em geral.

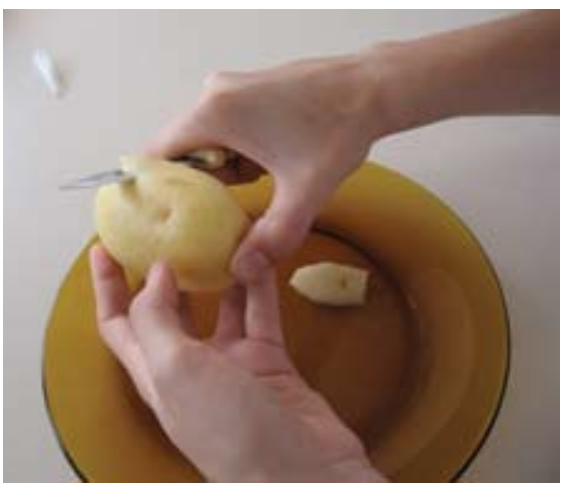

Figura 1 - Tarefa de descascar batatas sem o uso da adaptação.

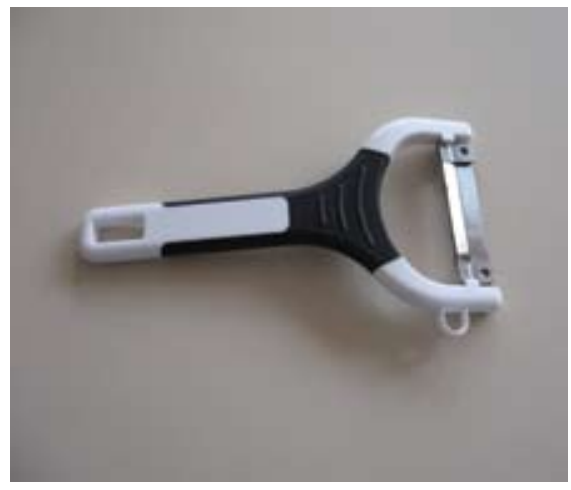

Figura 2 - Vista superior da adaptação.

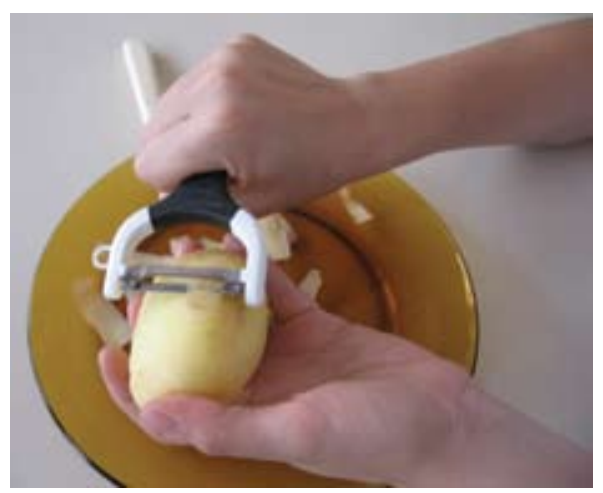

Figura 3 - Tarefa de descascar batatas com o uso da adaptação.

\section{REFERÊNCIAS}

1. Bonsentka DJ. Pathogenesis of osteoarthritis. In: Hunter JM, et al. Rehabilitation of the hand and upper extremity. 5 ed. St. Louis: Mosby. V 2, 1637-1645p.

2. Burkholder JF. Osteoarthritis of the hand: a modifiable disease. J Hand Theraty 2000 April - June; 79-89.
3. Melvin, JL, Ferrel KM. Adult rheumatic diseases. Bethesda: AOTA; 2000. 365p.

4. Napier JR. A mão do homem: anatomia, função, evolução. Rio de Janeiro: Zahar Editores; 1983. 182p.

5. Yasuda YL. Artrite Reumatóide e Osteoartrite. In: Trombly C. Terapia ocupacional para disfunções físicas. Rio de Janeiro: Santos Editora; 2005. 1001-1204p.

\footnotetext{
1. Professora do Departamento de Terapia Ocupacional da Escola de Educação Física, Fisioterapia e Terapia Ocupacional da Universidade Federal de Minas Gerais (UFMG) e coordenadora do Projeto de Extensão "Grupo de Orientação aos Indivíduos Acometidos por Doenças Reumáticas"

2. Acadêmica do curso de Terapia Ocupacional da Universidade Federal de Minas Gerais (UFMG) e bolsista do Projeto “Grupo de Orientação aos Indivíduos Acometidos por Doenças Reumáticas"

Endereço para correspondência: Professora Johanna Noordhoek, Rua Mármore, 362/404, Santa Teresa, CEP: 31010-220, Belo Horizonte, Minas Gerais,
} e-mal: johannanoord@yahoo.com.br 